\title{
40 years IUPESM
}

\section{The International Union for Physical and Engineering Sciences in Medicine}

\author{
James CH Goh ${ }^{1}$. Slavik D. Tabakov
}

Published online: 25 October 2020

(c) IUPESM and Springer-Verlag GmbH Germany, part of Springer Nature 2020

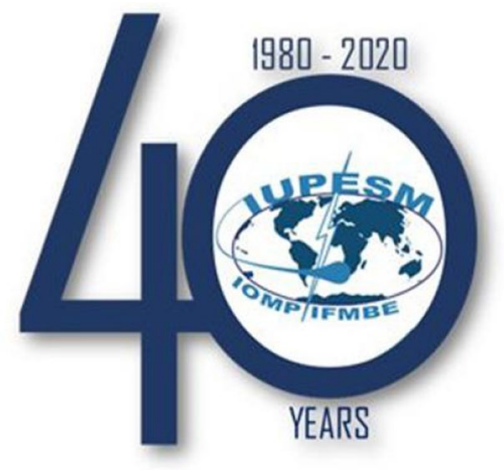

\section{The formation of IUPESM}

The two very closely related professional organisations, i.e. the International Federation for Medical and Biological Engineering (IFMBE) and the International Organization for Medical Physics (IOMP) were formed respectively in 1959 and in 1963 [1,2]. These organisations aimed at coordinating the international advancement of the two sister professions: Biomedical Engineering and Medical Physics. During the 1970s, it was recognised that a long-term strategic decision was needed for official recognition of their scientific disciplines. This prompted the formation of a Union of both professions. This Union could then achieve recognition of both scientific disciplines through membership to the International Council of Scientific Unions (ICSU).

To pursue the formation of the Union, a joint committee was formed in 1975 with IOMP represented by Prof. R. L. Clarke, and IFMBE represented by Dr. J. A. Hopps. The

James CH Goh

biegohj@nus.edu.sg

National University of Singapore, Singapore, Singapore

2 King's College London, London, UK committee produced a draft proposal and had initially proposed the name of the Union as "The International Union for Physics and Engineering in Medicine". A joint IOMP/ IFMBE meeting was held in 1976, during the $4^{\text {th }}$ International Conference on Medical Physics (ICMP) at Ottawa, Canada to discuss the proposal. The $4^{\text {th }}$ ICMP was organised specifically in tandem with the IFMBE's $11^{\text {th }}$ International Conference on Medical and Biological Engineering Conference at the same venue in Ottawa.

These activities continued and both organisations (IOMP and IFMBE) agreed to hold their 1979 International Conferences together in Jerusalem. These were the $5^{\text {th }}$ International Conference on Medical Physics (ICMP) and the $12^{\text {th }}$ International Conference on Medical and Biological Engineering (ICMBE). This joint event in Jerusalem was recognised as the 1st World Congress on Medical Physics and Biomedical Engineering. It was during this joint activity in Jerusalem, the Councils of both organisations discussed and agreed to the draft Statutes of the International Union for Physical and Engineering Sciences in Medicine (IUPESM).

In January 1980, IUPESM was established as an Organisation uniting medical physicists and biomedical engineers. Its Founding President was chosen to be the then IOMP President - Prof. John Mallard (UK), who had taken an active part in forming the Union. At that time the joint membership of IUPESM (i.e. IOMP and IFMBE) was about 20,000 members in 54 countries.

\section{Global recognition of the scientific disciplines of medical physics and biomedical engineering}

The International Council of Scientific Unions (ICSU) is the oldest scientific Union (a non-governmental organisation) in the world. It was formed in 1931. Its membership increased over the years and by 2017 it had 122 multi-disciplinary 
National Scientific Members, Associates and Observers, representing 142 countries and 31 International Scientific Unions (in variety of disciplines) and 22 Scientific Associates. Becoming a member of ICSU brings recognition to a particular scientific discipline. With this in mind, the officers of IUPESM initiated immediately the process of ICSU membership of the two scientific disciplines, i.e. medical physics and biomedical engineering.

Prof. John Mallard presented a brief outline of this very important and long process in his article, "The Birth of the International Organizations-with Memories" [3]. The first application of IUPESM to ICSU was supported by the National Science Academies of USA, Canada, Sweden and UK (the societies of these countries are founding members of IOMP). The application was also supported by several Scientific Unions member of ICSU - the International Union of Pure and Applied Physics, the International Union of Pure and Applied Chemistry and the International Union of Biochemistry and Molecular Biology. The application was accepted in-principle with the condition of an assessment period. Following this, the first application was withdrawn, allowing the submission of the application for Associate Membership to ICSU. This second application was made in 1982 and, in 1983 IUPESM was accepted as an ICSU Associate Member.

In 1997, a meeting was held between ICSU and IUPESM to review the past period in which IUPESM had been an Associate Member. Subsequently, IUPESM was allowed to submit a new application for Full Membership. This part of the process was championed by Prof. Keith Boddy - the then IUPESM President (and Past-President of IOMP). This substantial application was submitted in 1999. Based on it the Council of ICSU accepted unanimously IUPESM as a Full Member. During September 1999 IUPESM became the 27th Scientific Union member of ICSU. This major success crowned the $20^{\text {th }}$ Anniversary of IUPESM in 2000 with the recognition for our scientific disciplines. During the 20 years after this achievement, IUPESM has sustained its active status in ICSU and has taken part in all ICSU meetings. In 2008 ICSU elected one of the IUPESM representatives (Prof. Dov Jaron, Vice-President IUPESM in 2003-2006 and Past-President of IFMBE), as a member of its Executive Committee.

In 2018, ICSU merged with the International Social Science Council (ISSC). The merger saw the formation of the International Science Council (ISC). Following this IUPESM became a Full Member of the ISC, the world largest scientific organisation.

\section{Global recognition of medical physicists and biomedical engineers}

Following the recognition of the two scientific disciplines (i.e. medical physics and biomedical engineering), IUPESM moved to the next very important step of achieving global recognition of both professional occupations, i.e. medical physicists and biomedical engineers by the International Labour Organization (ILO) in Geneva. It was through ILO, that the professional occupations could be included in the International Standard Classification of Occupations (ISCO).

In many countries, governmental agencies utilise the definition and classification of professional occupations in the ISCO for organizing jobs into a clearly defined set of groups according to the tasks and duties undertaken in the job. It is also for recruitment of human resources, the management migration of workers between countries and the development of educational and training programmes. The listings in ISCO (a document of over 400 pages) assign specific code numbers to each recognised professional occupation. The lack of such specific codes for medical physicists or biomedical engineers resulted in the fact that in many countries our colleagues were employed under different names/codes, resulting in an undesirable employment and inability to have recognised training. This led to the situation that a number of colleagues being employed in positions at lower level and remuneration. Therefore, it is of great importance that the medical physics and biomedical engineering professions are classified and listed in the ISCO.

The discussions with ILO took over a decade, and many IUPESM officers spent considerable time and effort for this activity, among them Prof. Colin Orton, Prof. Azam Niroomand-Rad, Prof. Joahim Nagel, Prof. Fridtjof Nuesslin and Prof. Peter Smith.

The initial intention to include our professions in the listing of Health professionals appeared to be a long and arduous path. After many discussions, ILO decided to align our two professions with the science and engineering professional occupations. However, they agreed to add specific notes to the new ISCO-08, specifying that professionals in medical physics and biomedical engineering are strongly aligned with the other health professions.

The new ISCO-08 was published and distributed in 2012. In this publication, medical physicists are listed under Unit Group 2111, and biomedical engineers under Unit Group 2149. This was another huge achievement of IUPESM [4].

This great achievement of IUPESM was marked by IOMP establishing the International Day of Medical Physics (IDMP) on the 7th November (the birthday of Maria 
Sklodowska Curie). Starting from 2013 this Professional Day is celebrated globally. In 2016, IFMBE announced the establishment of the Global Clinical Engineers Day which is celebrated annually on 21 October.

\section{World Congresses and other IUPESM activities}

Since its formation, a main task of IUPESM has been to lead and coordinate the organisation of the triennial "World Congress on Medical Physics and Biomedical Engineering". The Union has organized all World Congresses since 1979 (Jerusalem) and is currently preparing for the coming World Congress in Singapore which is originally scheduled for mid-2021. In view of the outbreak of COVID-19 pandemic in late 2019. It is expected that the massive restriction of travel and border closure will overflow into 2021, therefore the World Congress in Singapore looks set to be postponed to mid-June 2022. The list of all World Congresses is as follows:

1st World Congress: Jerusalem, Israel, August 19-24, 1979

2nd World Congress: Hamburg, Federal Republic of Germany, September 5-11, 1982

3rd World Congress: Espoo, near Helsinki, Finland, August 11-16, 1985

4th World Congress: San Antonio, USA, August 6-13, 1988

5th World Congress: Kyoto, Japan, July 7-12, 1991

6th World Congress: Rio de Janeiro, Brazil, August 21-26, 1994

7th World Congress: Nice, France, September 14-19, 1997

8th World Congress: Chicago, USA, July 25-28, 2000

9th World Congress: Sydney, Australia, August 24-19, 2003

10th World Congress: Seoul, Korea, August 27 - September 1, 2006

11th World Congress: Munich, Germany, September 7-12, 2009

12th World Congress: Beijing, China, May 26-31, 2012

13th World Congress: Toronto, Canada, June 7-12, 2015

14th World Congress: Prague, Czech Republic, 3-8 June 2018

15th World Congress: Singapore, 11-17 June 2022.

\section{Establishment of IUPESM Journal "Health \& Technology" and other activities}

In 2005, Prof. J Nagel (IUPESM President 2006-2009) initiated the creation of the IUPESM Journal "Health and Technology". Following several years of discussion with the publisher, Springer-Nature, the journal was finally launched in 2011. The broad profile of the Journal established itself as a platform for collaboration between medical physicists, engineers and other related professions [5].

There were other publications over the years, these were associated with the specific Committees of IUPESM. For example, the Education and Training Committee's effort to synchronise education and training activities of both Medical Physics and Biomedical Engineering professions resulted in a 2011 publication of a book on academic programs in various countries (Ed. S Tabakov, P Sprawls, A Krisanachinda, C Lewis) [6].

In 2012, IUPESM set up a Health Technology Task Group (HTTG) with the intention of assisting countries to define their health technology needs, and identifying and rectifying health system constraints for adequate management and utilization of health technology, particularly through training, capacity building and the development and application of appropriate technology. In 2017, the HTTG published the book "Defining the Medical Imaging Requirements for a Rural Health Center" (Ed. C Borras) [7].

In 2019 IUPESM set up a sequence of regular meetings/ workshops (coordinated by KP Lin and M Stoeva) aiming to increase collaboration between medical physicists and engineers. So far two such Workshops were organised successfully in Taipei (Fig. 1) and in Rome, and further two are planned.

\section{IUPESM structure and officers}

The IUPESM General Assembly is the highest authority of the Union and determines its general policy. It consists of representatives of the Constituent Organizations. The Administrative Council (AC) conducts the business of the IUPESM between sessions of the General Assembly The current members of IUPESM Administrative Council (Fig. 2) are: Prof James Goh (President, Singapore), Prof Slavik Tabakov (Vice-President, UK), Prof Kin Yin Cheung (Past-President, Hong Kong), Prof Leandro Pecchia (Secretary General, UK), Prof Magdalena Stoeva (Treasurer, Bulgaria), Prof Madan Rehani (President IOMP, USA), Prof Shankar Krishnan (President IFMBE, USA), Prof John Damilakis (Vice-President IOMP, Greece), Prof Ratko Magjarevic (Vice-President IFMBE, Croatia), Prof Eva Bezak (Secretary General IOMP, Australia), Prof Kang Ping Lin (Secretary General IFMBE, Chinese Taipei), Prof Geoffrey Ibbott (IOMP, USA), Prof Stephen Keevil (IOMP, UK), Prof Timo Jamsa (IFMBE, Finland) and Prof Marc Nyssen (IFMBE, Belgium). The current team works towards incorporation of IUPESM. 


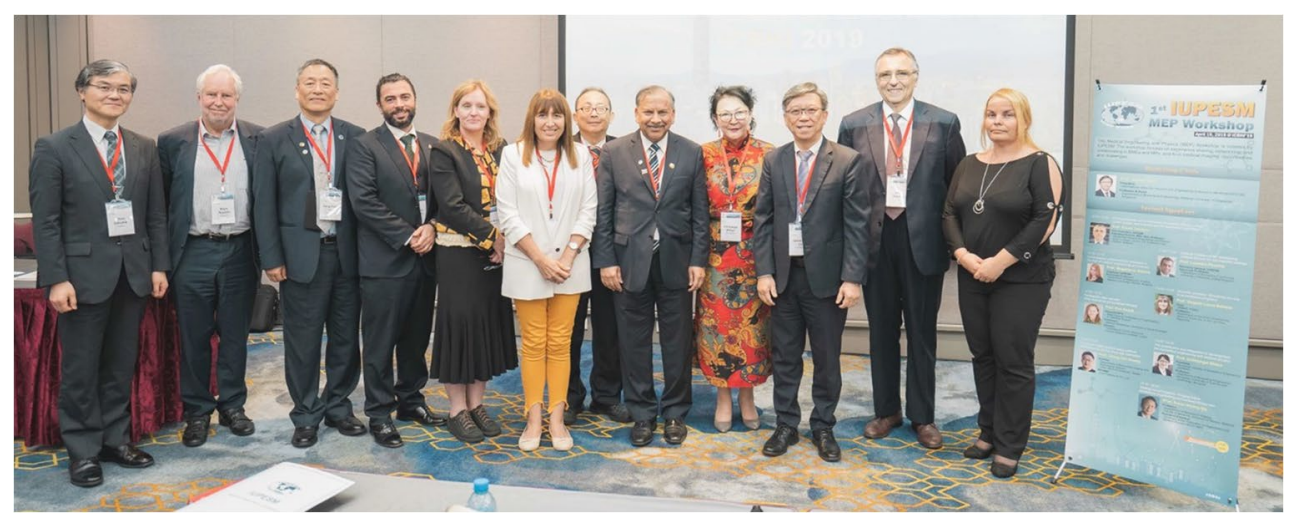

Fig. 1 Organisers and keynote speakers of the first IUPESM collaborative Workshop, satellite to the ICBHI, 19 April 2019, Taipei



Fig. 2 Part of the IUPESM Administrative Council (office 2018-2021) at World Congress on Medical Physics and Biomedical Engineering, 3-8 June 2018, Prague

All IUPESM activities are collaborative between the elected officers and AC members from both IOMP and IFMBE. Below is a list of all past IUPESM Officers:

1982 - 1985:

President: John Mallard, UK (IOMP)

Vice-President: Masao Saito, Japan (IFMBE)

Secretary-General/Treasurer: Robert Clarke, Canada (IOMP)

\section{5 - 1988:}

President: Oivind Lorentsen, Norway (IFMBE)

Vice-President: Alexander Kaul, Germany (IOMP)
Secretary-General/Treasurer: Jack Hopps, Canada (IFMBE)

Past President: John Mallard, UK (IOMP)

\section{8 - 1991:}

President: Lawrence H. Lanzl, USA (IOMP)

Vice-President: Nandor Richter, Hungary (IFMBE)

Secretary-General/Treasurer: Robert Clarke, Canada (IOMP)

Past President: Oivind Lorentsen, Norway (IFMBE) 
President: Robert Nerem, USA (IFMBE)

Vice President: John Cunningham, Canada (IOMP)

Secretary-General/Treasurer: Orest Roy, Canada (IFMBE)

Past President: Lawrence H. Lanzl, USA (IOMP)

1994 - 1997:

President: Niilo Saranummi, Finland (IFMBE)

Vice-President: Udipi Madhvanath, India (IOMP)

Secretary-General/Treasurer: Jos Spaan, Netherlands (IOMP)

Past President: Robert Nerem, USA (IFMBE)

1997 - 2000:

President: Keith Boddy, UK, (IOMP)

Vice-President: Fumihiko Kajiya, Japan (IFMBE)

Secretary-General/Treasurer: Gary Fullerton, USA (IOMP)

Past President: Niilo Saranummi, Finland (IFMBE)

2000-2003:

President: Jean-Pierre Morucci, France (IFMBE)

Vice-President: Colin Orton, USA (IOMP)

Secretary-General/Treasurer: Gary Fullerton, USA

(IOMP)

Past President: Keith Boddy, UK (IOMP)

\section{3-2006:}

President: Colin Orton, USA / Oskar Chomicki, Poland (IOMP)

Vice-President: Dov Jaron, USA (IFMBE)

Sec-General/Treasurer:Heikki Terio, Sweden (IFMBE)

Past President: Jean-Pierre Morucci, France (IFMBE)

2006-2009:

President: Joachim Nagel, Germany (IFMBE)

Vice-President: Azam Niroomand-Rad, USA/Barry Allen, Australia, (IOMP)

Secretary-General: Heikki Terio, Sweden (IFMBE)

Treasurer: Peter Smith, UK (IOMP)

Past-President: Colin Orton, USA (IOMP)

2009-2012:

President: Barry Allen, Australia (IOMP)

Vice-President: Makoto Kikuchi, Japan (IFMBE)

Secretary-General: Heikki Terio, Sweden (IFMBE)

Treasurer: Slavik Tabakov, UK (IOMP)
Past-President: Joachim Nagel, Germany (IFMBE)

2012 - 2015:

President: Herb Voigt (IFMBE)

Vice-President: Fridtjof Nusslin (IOMP)

Secretary-General: James Goh (IFMBE)

Treasurer: Peter Smith (IOMP)

Past-President: Barry Allen, Australia (IOMP)

2015 - 2018:

President: K. Y. Cheung, Hong Kong (IOMP)

Vice-President: Ratko Magjarevic, Croatia (IFMBE)

Secretary-General: Howell Round, New Zealand (IOMP)

Treasurer: Mark Niessen, Belgium, (IFMBE)

Past President: Herb Voigt, USA (IFMBE)

2018 - 2021:

President: James Goh, Singapore (IFMBE)

Vice-President: Slavik Tabakov, UK (IOMP)

Secretary-General: Leandro Pecchia, UK (IFMBE)

Treasurer: Magdalena Stoeva, Bulgaria (IOMP)

Past-President: K Y Cheung, Hong Kong (IOMP)

\section{Conclusion}

The global recognition and collaborative activities of both professions, i.e. medical physicists and biomedical engineers could only be achieved by the formation of IUPESM. Over the last 40 years, many of our colleagues have contributed significantly to the development of IUPESM. To mark their achievements the IUPESM Awards Committee (comprise of S Tabakov (Chair), J Goh, S Renha, R Magjarevic, KY Cheung) had developed a new Fellowship scheme recognising outstanding contribution to the international development of Physical and Engineering Sciences in Medicine. The FIUPESM scheme will be inaugurated on 20 Nov 2020.

On behalf of its Constituent Organisations, IUPESM currently represents an estimated total of 150,000 professionals from over 100 countries in ISC and ILO. Over these 40 years, the overall number of the professionals, serving healthcare globally, has increased over 7 folds. IUPESM is grateful to all colleagues who served its offices and committees over these 40 years, and proudly continues to contribute to the advancement of physical and engineering science in medicine for the benefit and wellbeing of humanity. 


\section{Compliance with ethical standards}

Conflict of interest The authors declare that they have no conflict of interest.

\section{References}

1. Voigt H, Magjarevic R (Eds). Launching IFMBE into the 21st century: 50 years and counting. Springer; 2009.

2. Niroomand-Rad A, Orton C, Smith P, Tabakov S. A History of the International Organisation for Medical Physics - 50 Years Anniversary - Part II. J Med Phys Int. 2014;2:7-17.

3. Mallard J. The Birth of the International Organizations - with Memories. Scope. 1994;3(2):25-31.

4. Smith P, Nuesslin F. Benefits to Medical Physics from the Recent Inclusion of Medical Physicists in the International
Classification of Standard Occupations (ICSO-08). Med Phys Int J. 2013;1(1):11.

5. Journal Health and Technology, Springer. https://www.springer. com/journal/12553.

6. Tabakov S, Sprawls P, Kirsanachinda A, Podgorsak E, Lewis C. IOMP model curriculum for postgraduate (MSc-level) education programme on Medical Physics, in Medical Physics and Engineering Education and Training - part I, ICTP, Trieste, ISBN 92-95003-44-6; 2011.

7. Borras C (Ed). Defining Medical Imaging Requirements for a Rural Health Center, Springer, ISBN 978-981-10-1611-0; 2017.

Publisher's note Springer Nature remains neutral with regard to jurisdictional claims in published maps and institutional affiliations. 